\title{
The use of progesterone during pregnancy to prevent preterm birth
}

Eman S. Alsulmi, MBBS, FRCSC, Malikah Alfaraj, MBBS, FRCSC, Yaser Faden, MD, SBOG, Noura Al Qahtani, MD, FRCOG.

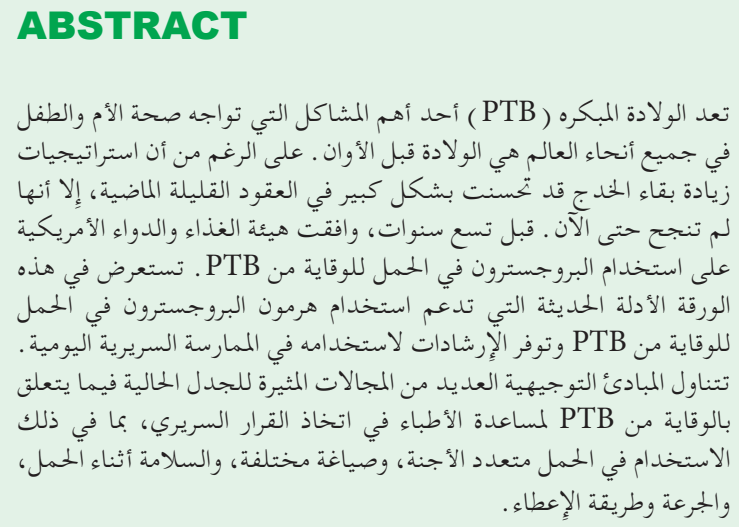

One of the most significant problems facing maternal and children health worldwide is preterm birth (PTB). Although strategies to increase the survival of premature infants have significantly improved in the past few decades, they have yet to be successful. Nine years ago, the use of progesterone in pregnancy was approved by the United States Food and Drug Administration (FDA) for PTB prevention. This paper reviews the recent evidence supporting the use of progesterone in pregnancy for PTB prevention and provides guidelines for its use in daily clinical practice. The guidelines address multiple current controversial areas regarding the prevention of $\mathrm{PTB}$ to aid physicians with their clinical decision-making practice, including the use in multifetal gestation, different formulations, safety in pregnancy, dose and route of administration.

Keywords: progesterone, vaginal progesterone, 17-alpha-hydroxy-progesterone caproate, short cervix, preterm birth

Saudi Med J 2020; Vol. 41 (4): 333-340 doi: $10.15537 /$ smj.2020.4.25036

From the Department of Obstetrics and Gynecology (Alsulmi, Alqahtani), King Fahd Hospital of the University, Imam Abdulrahman Bin Faisal University, Dammam; from the Department of Obstetrics and Gynecology (Alfaraj), Johns Hopkins Aramco Healthcare, Dhahran; and from the Department of Obstetrics and Gynecology (Faden), King Abdulaziz Medical City, King Saud Bin Abdulaziz University for Health Sciences, Ministry of National Guard - Health Affairs, Jeddah, Kingdom of Saudi Arabia.
Received 30th July 2019. Accepted 4th February 2020.

Address correspondence and reprint request to: Dr. Eman Alsulmi, Department of Obstetrics and Gynecology, King Fahd Hospital of the University, Imam Abdulrahman Bin Faisal University, Dammam,

Kingdom of Saudi Arabia.E-mail: ealsulmi@gmail.com

ORCID ID: https://orcid.org/0000-0001-9416-277X

$T$ The definition of preterm birth (PTB) is delivery before 37 weeks' gestation. Since PTB is a major cause of worldwide neonatal mortality and morbidity, its prevention is of high priority in obstetric care. ${ }^{1}$ It is estimated that 15 million preterm babies are born annually, with PTB rates ranging from $5 \%$ to $18 \%{ }^{2}$ In Saudi Arabia, the PTB rate was approximately $6 \%$ in 2010. ${ }^{3}$ Nationally, PTB complications are also the foremost reason behind neonatal mortality, accounting for approximately $54 \%$ of the cases in $2008 .{ }^{4}$

Progesterone's role in PTB prevention has been the subject of several randomized controlled trials (RCTs) over the past few years. These trials examined pregnancies at high risk for spontaneous PTB (SPTB) in the setting of a prior SPTB or presence of short cervix, as confirmed by the use of ultrasound during the routine mid-trimester scan.

The purpose of this guideline is to provide evidence-based information for practitioners involved in the care of pregnant women with regard to the use of progesterone to reduce recurrent SPTB risk and aid in clinical decision-making.

Evidence. Relevant RCTs, systematic reviews, and meta-analysis were searched for in MEDLINE, PubMed, and Cochrane Library, with a restriction to articles published between 1996 and 2019. Relevant Medical Subject Headings (MeSH) combined with a Keyword search were used to comb the databases. The search was limited to the English language.

Grading of Recommendations Assessment, Development and Evaluation (GRADE) approach was used to assess the quality of evidence and strength 
of recommendations, which is now considered the standard in guideline development (Table 1).

Table 1 - Grading of Recommendations Assessment, Development and Evaluation (GRADE) approach was used to assess the quality of evidence and strength of recommendations.

\begin{tabular}{ll}
\hline Grade & \multicolumn{1}{c}{ Definition } \\
\hline 1A & Strong recommendation based on high-quality evidence \\
1B & Strong recommendation based on moderate-quality evidence \\
1C & $\begin{array}{l}\text { Strong recommendation based on low- or very-low-quality } \\
\text { evidence }\end{array}$ \\
2A & Weak recommendation in presence of high-quality evidence \\
2B & Weak recommendation in presence of moderate-quality evidence \\
2C & $\begin{array}{l}\text { Weak recommendation in presence of low- or very-low-quality } \\
\text { evidence }\end{array}$ \\
\hline
\end{tabular}

Mechanism of action. Progesterone displays biological effects on the myometrium and uterine cervix. ${ }^{5}$ Through animal studies, several researchers have proposed that progesterone withdrawal or a decline in its action is a key control mechanism for cervical ripening. ${ }^{6-9}$

Though the precise mechanism of action of progesterone in the prevention of PTB is still unidentified, there are 2 widely accepted mechanisms. The first is a local anti-inflammatory effect at the maternal-fetal interface that counteracts the inflammation process leading to PTB, while the second is the ability to modulate other biological processes implicated in cervical ripening. ${ }^{6,10}$

Safety data on progesterone use in pregnancy. The safety of progesterone use in its synthetic or natural form in the first trimester of pregnancy is outside the scope of this guideline, and thus, will not be discussed.

Current evidence suggests that starting progesterone therapy after 14 weeks' gestation is safe for both the mother and fetus. The OPPTIMUM trial found that at the age of 24 months' children exposed to vaginal progesterone in utero have no significant differences in neurodevelopmental outcomes compared to controls in the same age group. ${ }^{11}$ Similarly, the observation of

Disclosure. Authors have no conflict of interests and the work was not supported or funded by any drug company. children with in utero exposure to 17-alpha-hydroxyprogesterone caproate (17-OHPC) up to 4 years of age did not reveal any detrimental effects. ${ }^{12}$

What is the role of progesterone in singleton pregnancies with no history of PTB and unknown cervical length? A small group of 168 women with no history of PTB and unknown cervical length (CL) was given a weekly dose of 17-OHPC beginning at 16-20 weeks. A beneficial effect compared to placebo was not observed. ${ }^{13}$

We could not find an RCT that examined the effect of vaginal progesterone in this group of women.

In low risk women with singleton gestations, no history of SPTB and unknown or normal CL there is no evidence to support the use of progesterone for PTB prevention. Therefore, it is not recommended to use progesterone in low-risk women for prevention of PTB. (Grade 2C)

What is the role of progesterone in singleton pregnancies with no history of PTB, but a short cervical length at 18-24 weeks? Cervical shortening detected with transvaginal ultrasound in the mid-trimester is a strong predictor of SPTB. ${ }^{14}$

Grobman found that a weekly $250 \mathrm{mg}$ intramuscular injection (IM) of 17-OHPC in nulliparous women with singleton gestations and transvaginal ultrasound cervical length (TVU CL) of $<30 \mathrm{~mm}$ at $16-22$ weeks was not superior to placebo for PTB prevention at $<35$ weeks and $<37$ weeks. ${ }^{15}$

Several large RCTs have shown a significant reduction in SPTB risks among asymptomatic women who received vaginal progesterone following transvaginal ultrasound diagnosis of a short cervix. ${ }^{16-19}$

A meta-analysis by Romero et $\mathrm{al}^{20}$ showed a significant PTB risk reduction in women with a TVU CL equal to or less than $25 \mathrm{~mm}$ who started vaginal progesterone (from $27.5 \%$ to $18.1 \%$ ). ${ }^{20}$ Romero et $\mathrm{al}^{21}$ included the OPPTIMUM trial in their recently published meta-analysis and found a decrease in the risk of PTB at less than 33 weeks in singleton gestations with a sonographic short cervix of less than $25 \mathrm{~mm}$ (14\% versus [vs.] 22\%). Furthermore, vaginal progesterone significantly decreased PTB risk at $<36$ weeks of gestation. Vaginal progesterone was also found to decrease the risk of neonatal respiratory 
distress syndrome, birthweights of less than $1500 \mathrm{~g}$ and $2500 \mathrm{~g}$, and neonatal intensive care unit admission. ${ }^{21}$

Romero et $\mathrm{a}^{21}$ also found that a vaginal progesterone gel with a daily dose of $90 \mathrm{mg}$ has a similar compared to a daily $200 \mathrm{mg}$ of vaginal progesterone tablets in the reduction of PTB risk and composite neonatal adverse outcome. ${ }^{21}$ Therefore, there is not enough evidence to support the use of one vaginal progesterone preparation or dose over the other.

Women with singleton gestations, no history of SPTB, and sonographic short cervix (TVUCL $\leq 20 \mathrm{~mm}$ ), and $<24$ weeks of gestation may benefit from vaginal progesterone to reduce PTB risk, perinatal morbidity, and mortality (Grade 2B).

Patients can be given $90 \mathrm{mg}$ vaginal progesterone gel or $200 \mathrm{mg}$ vaginal progesterone tablet or suppository once per day, preferably at bedtime. (Grade 2B).

Using weekly intramuscular 17-OHPC injection is not recommended for this group of women (Grade 2C).

What is the role of progesterone in singleton pregnancies with prior PTB? In women with a history of SPTB, most studies suggest a significant risk reduction in PTB, perinatal mortality, and major morbidity among pregnant women treated with progesterone regardless of its route of administration. .2-32 $^{2}$

Meis et $\mathrm{al}^{30}$ found that an IM weekly administration of $250 \mathrm{mg}$ of 17-OHPC, starting at 16-20 6/7 weeks of gestation, was linked to a $34 \%$ decrease in recurrent PTB at $<37$ weeks of gestation compared to placebo in women with singleton pregnancies and a history of SPTB at 20-36 6/7 weeks of gestation. Progesterone was also found to positively correlate with significant decreases in both overall PTB and neonatal complications. ${ }^{30}$

The OPPTIMUM trial found that the use of vaginal progesterone in women with a history of SPTB was not associated with a statistically significant decrease in the risk of PTB, nor did it affect the rate perinatal mortality and morbidity (progesterone $15.9 \%$ vs. placebo $18.8 \%){ }^{11}$

Three studies that directly compared 17-OHPC and vaginal progesterone in women with prior SPTB have been published in the literature. ${ }^{33-35}$ Saccone et $\mathrm{al}^{36}$ included these studies in a meta-analysis which consisted of 680 women in total. The largest trial, conducted in
Saudi Arabia, accounted for $74 \%$ of subjects in the meta-analysis. ${ }^{35}$ They concluded that in women with singleton pregnancies and a history of SPTB, a daily vaginal progesterone can be used as an alternative to weekly 17-OHPC injection for SPTB prevention. The significant heterogeneity between study findings, attributed to the multifactorial origin of SPTB, should be taken into consideration when interpreting such data. Some studies have also examined the role of vaginal progesterone in this setting ${ }^{35,37}$ while others used 17-OHPC. ${ }^{30,38}$

A double-blind, placebo-controlled, international (PROLONG) trial published in 2019 found no benefit of weekly IM injection of $250 \mathrm{mg}$ of 17-OHPC (from 16 to 36 weeks of gestation) compared to placebo in decreasing recurrent PTB risk and neonatal morbidity when given to women with singleton gestation and a history of SPTB. ${ }^{39}$

In women with a singleton gestations and a history of SPTB at 20-36 $6 / 7$ weeks of gestation, the use of 17-OHPC $250 \mathrm{mg}$ intramuscular weekly injection, starting at 16-24 weeks until 36 weeks of gestation is recommended (Grade $2 \mathrm{~B}$ ).

Vaginal progesterone preparations may be considered as an alternative if 17-OHPC is not available for this group of women (Grade 2C).

What is the role of progesterone in singleton pregnancies with a history of PTB and short CL? In women with singleton pregnancies, short cervix (TVU CL $<15 \mathrm{~mm}$ ) and a history of PTB, Fonseca et $\mathrm{al}^{40}$ compared vaginal progesterone to placebo and found no statistical significant difference in the SPTB rate at $<34$ weeks of gestation. Similarly, in 2011, the PREGNANT trial by Hassan et $\mathrm{al}^{41}$ found that in women with a history of PTB and TVU CL $<20 \mathrm{~mm}$, vaginal progesterone was not linked to a significantly lower rate of PTB. Moreover, in a subgroup analysis of a meta-analysis by Romero et $\mathrm{al}^{42}$ the beneficial effect of vaginal progesterone did not significantly differ between women with a short cervix and a history of SPTB and those without a prior SPTB. Berghella et $\mathrm{al}^{42}$ conducted a trial that failed to demonstrate any benefit of 17-OHPC in women with a history of SPTB and a cerclage for short cervix (TVU CL $<25 \mathrm{~mm}$ ). Although, in women without a cerclage 17-OHPC appears to play a role in reducing pre-viable birth and perinatal mortality. ${ }^{43}$ 
In a study by Conde-Agudelo et $\mathrm{al}^{44}$ evaluating both interventions including vaginal progesterone and cervical cerclage, the effectiveness of both interventions was similar in reducing the risk of SPTB and perinatal adverse outcome in women with a mid-trimester sonographic short cervix, singleton gestation, and prior PTB.

In women with a prior SPTB who began the 17-OHPC treatment, the continuation of 17-OHPC therapy throughout pregnancy, regardless of the cervical length (with or without placement of cervical cerclage when indicated), is recommended (Grade 2B).

In women with a previous SPTB and TVU CL $<25 \mathrm{~mm}$ as detected on a transvaginal ultrasound at 18-24 weeks of gestation, a daily administration of $200 \mathrm{mg}$ of vaginal progesterone is recommended. That is appropriate only if the patients have not yet commenced 17-OHPC treatment (Grade 2B).

What is the role of progesterone in twins and higherorder multiple pregnancies? Randomized trials of 17-OHPC to primarily prevent PTB in twin pregnancy with unknown CL have not established its efficacy to prevent PTB or reduce overall twin morbidity resulting from prematurity. ${ }^{45,46}$ The PROGESTWIN study showed that intramuscular 17-OHPC therapy did not reduce PTB before 37 weeks in unselected twin pregnancies. Nevertheless, intramuscular 17-OHPC significantly decreased neonatal morbidity and increased birth weight. ${ }^{47}$

The use of 17-OHPC in unselected triplet pregnancies did not result in a statistically significant difference in the rate of SPTB in the 17OHPC group compared to the placebo group. ${ }^{48,49}$ This finding was observed regardless of history of PTB, method of conception, or type of chorionicity. Similarly, 17-OHPC did not reduce PTB in twin pregnancies with sonographic short cervix (TVU CL $<25 \mathrm{~mm}$ )..$^{50}$

A randomized controlled trial by Senat et $\mathrm{al}^{51}$ showed that increasing progesterone dose for women with twin pregnancy was linked to a statistically significant increase in early PTB at $<32$ weeks of gestation in the intent-to-treat analysis (29\% treated vs. $12 \%$ control, 2.5 -fold increase, $p=0.007) .{ }^{51}$ Additionally, the treated group observed a statistically substantial increase in the rate of perinatal mortality and a composite adverse outcome of stillbirth and respiratory distress. ${ }^{52,53}$

Studies on vaginal progesterone use in twin pregnancy failed to show a significant decrease in PTB risk, neonatal mortality, and morbidity. ${ }^{54-56}$ One study showed that when used for mid-trimester short cervix in twin pregnancies, vaginal progesterone does not lower the rate of PTB compared to placebo. ${ }^{57}$ However, in a meta-analysis by Romero and colleagues, the use of vaginal progesterone in women with mid-trimester sonographic short cervix (TVU CL $<25 \mathrm{~mm}$ ) did not positively impact PTB rate before 33 weeks' gestation, but was associated with a $48 \%$ decrease in neonatal mortality and complications. It also showed a drop in PTB risk in women $<37$ weeks' gestation with a twin pregnancy and no prior PTB. ${ }^{58-60}$

Romero eta ${ }^{61}$ demonstrated, in an updated individual patient data meta-analysis, a significant reduction of both PTB risk at $<33$ weeks of gestation by $31 \%$ and neonatal death by $47 \%$ when vaginal progesterone administered to women with a twin pregnancy and an asymptomatic mid-trimester sonographic short cervix (TVU CL $<25 \mathrm{~mm}$ ). Moreover, vaginal progesterone group was found to have a significant reduction in global SPTB risk, perinatal death, and composite neonatal adverse outcome. ${ }^{61}$

In women with multiple gestations, prophylactic progesterone is
ineffective in PTB prevention or reduction of overall twin morbidity
(Grade 1B).
Increasing the 17-OHPC dose for women with twin pregnancy may be
harmful (Grade 2C).
Women with twin pregnancy and sonographic short cervix treated with
vaginal progesterone had a nominal drop in PTB risk at $<33$ weeks and a
significant reducing in composite neonatal adverse outcome (Grade 1B).
There is limited information regarding the use of progesterone to prevent
the recurrence of PTB in multiple pregnancies where there is a prior the recurrence of
history of SPTB.

What is the role of progesterone in patients with preterm premature rupture of membranes (PPROM)?

Progesterone supplementation exhibits no benefit in the prevention of SPTB in women with PPROM. A large meta-analysis failed to demonstrate a prolonged latency period or improvement in maternal or neonatal outcomes. ${ }^{62}$

In women with PPROM, progesterone has not demonstrated any beneficial effect and is, therefore, not recommended (Grade 1A). 
What is the role of progesterone in patients present with preterm labor? A Cochrane systematic review of eight trials concluded that there is not enough evidence to encourage the use of progesterone to prevent PTB in women with threatened or experienced preterm labor. ${ }^{63}$ However, some data suggest that the use of progesterone reduced preterm deliveries $<37$ weeks of gestation and increased birthweight. Nevertheless, due to the relatively small number of available studies, the analysis was limited. The varying types, doses and administration routes of progesterone also limited the power of the meta-analysis.

There is currently not enough evidence to recommend progesterone use to prevent PTB in pregnancies complicated with PPROM or threatened/ established PTL.

What are the optimal doses and the ideal timing for the initiation and cessation of progesterone in the prevention of PTB? PTB prevention trials include the use of a variety of progesterone doses. Based on the US datasets, $250 \mathrm{mg}$ 17-OHPC is predominantly administered weekly via intramuscular injection. ${ }^{36}$
Vaginal progesterone is also available and may have the advantage of fewer systemic side effects, although reports of vaginal irritation have arisen due to this route. Nonetheless, doses of 90-400 mg have been used through this route of administration, but the optimal dosage has not been established. A subgroup analysis of the recent meta-analysis in 2018 by Romero showed no difference in effect between $90-100 \mathrm{mg}$ and $200 \mathrm{mg} / \mathrm{d}$ of vaginal progesterone for women with a short cervix. ${ }^{42}$

The timing of therapy varied between studies and began as early as week 16 of gestation in women with a previous history of PTB. In some trials, treatment began between weeks 16-24 of pregnancy when an ultrasound scan diagnosed the short cervix. Other studies show no difference in the efficacy of progesterone therapy when initiated at 16-20 weeks compared to 20-26 weeks. ${ }^{64,65}$ Rebarber found in a retrospective analysis that early interruption of 17-OHPC therapy has been shown to increase spontaneous recurrent PTB risk. ${ }^{66}$ Therefore, continued treatment until 36-37 weeks of gestation is recommended.

Progesterone therapy should begin at 16-24 weeks of gestation when indicated and continue until 36-37 weeks or delivery, whichever occurs first.

\section{Summary of recommendations and level of evidence:}

\begin{tabular}{|c|c|c|c|c|}
\hline Patients population & Vaginal progesterone & Level of evidence & $\begin{array}{c}\text { Intra-muscular } \\
\text { progesterone (17-OHPC) }\end{array}$ & Level of evidence \\
\hline Low risk pregnant women & Not recommended & Insufficient & Not recommended & Insufficient \\
\hline $\begin{array}{l}\text { Singleton pregnancy with only short } \\
\text { cervix }\end{array}$ & Recommended & Grade 2B & Not recommended & Insufficient \\
\hline Singleton pregnancy with prior SPTB & $\begin{array}{c}\text { May be considered as } \\
\text { alternative if } 17-\mathrm{OHPC} \\
\text { is not available }\end{array}$ & Grade 2C & Recommended & Grade 2B \\
\hline $\begin{array}{l}\text { Singleton pregnancy with prior SPTB } \\
\text { and short cervix }\end{array}$ & $\begin{array}{l}\text { Recommended if } 17- \\
\text { OHPC was not already } \\
\text { commenced }\end{array}$ & Grade 2B & $\begin{array}{l}\text { Recommended to continue } \\
\text { if it was already commenced } \\
\text { (with or without cervical } \\
\text { cerclage) }\end{array}$ & Grade 2B \\
\hline Unselected multiple pregnancy & Not-recommended & Grade 1B & Not-recommended & Grade 1B \\
\hline Multiple pregnancy with short cervix & Recommended & Grade 2B & Not recommended & Insufficient \\
\hline Multiple pregnancy with prior SPTB & Not recommended & Insufficient & Not recommended & Insufficient \\
\hline PPROM & Not recommended & Insufficient & Not recommended & Grade 1A \\
\hline Threatened PTB & Not recommended & Insufficient & Not recommended & Insufficient \\
\hline
\end{tabular}




\section{References}

1. World Health Organization. WHO recommended definitions, terminology and format for statistical tables related to the perinatal period and use of a new certificate for cause of perinatal deaths. Modifications recommended by FIGO as amended October 14, 1976. Acta Obstetricia Et Gynecologica Scandinavica 1977; 56: 247-253.

2. Blencowe H, Cousens S, Oestergaard MZ, et al. National, regional, and worldwide estimates of preterm birth rates in the year 2010 with time trends since 1990 for selected countries: a systematic analysis and implications. Lancet 2012; 379: 2162-2172.

3. World Health Organization. Country data and rankings for preterm birth data EMBARGO until May 2nd 2012. [cited 2012]. Available from: https://www.who.int/pmnch/media/ news/2012/201204_borntoosoon_countryranking.pdf

4. UNICEF. Saudi Arabia. Maternal, Newborn \& Child Survival. Saudi Arabia (KSA): Statistics and Monitoring Section/Policy and Practice; 2012. [cited 2012]. Available from: https://data. unicef.org/wp-content/uploads/country_profiles/Saudi\%20 Arabia/Maternal_SAU.pdf

5. Blanks AM, Brosens JJ. Progesterone action in the myometrium and decidua in preterm birth. Facts Views Vis Obgyn 2012; 4: $33-43$.

6. Xu H, Gonzalez JM, Ofori E, Elovitz MA. Preventing cervical ripening: the primary mechanism by which progestational agents prevent preterm birth? Am J Obstet Gynecol 2008; 198 : 314. e1-e8.

7. Nold C, Maubert M, Anton L, Yellon S, Elovitz MA. Prevention of preterm birth by progestational agents: what are the molecular mechanisms? Am J Obstet Gynecol 2013; 208: 223. e1-e7.

8. Kirby MA, Heuerman AC, Custer M, et al. Progesterone receptor-mediated actions regulate remodeling of the cervix in preparation for preterm parturition. Reprod Sci 2016; 23 : 1473-1483.

9. Yellon SM. Contributions to the dynamics of cervix remodeling prior to term and preterm birth. Biol Reprod 2017; 96: 13-23.

10. Zakar T, Mesiano S. How does progesterone relax the uterus in pregnancy? N Engl J Med 2011; 364: 972-973.

11. Norman JE, Marlow N, Messow C-M, Shennan A, Bennett PR, Thornton S, et al. Vaginal progesterone prophylaxis for preterm birth (the OPPTIMUM study): a multicenter, randomized, double-blind trial. Lancet 2016; 387: 2106-2116.

12. Northen AT,Norman GS, Anderson K, Moseley L, Divito M, Cotroneo M, et al. Follow-up of children exposed in utero to 17 alpha-hydroxyprogesterone caproate compared with placebo. Obstet Gynecol 2007; 110: 865-872.

13. Hauth JC, Gilstrap LC III, Brekken AL, Hauth JM. The effect of 17 alpha-hydroxyprogesterone caproate on pregnancy outcome in an active-duty military population. Am J Obstet Gynecol 1983; 146: 187-190

14. Committee on Practice Bulletins-Obstetrics TACoO, Gynecologists. Practice bulletin no. 130: prediction and prevention of preterm birth. Obstet Gynecol 2012; 120: 964-973.

15. Grobman WA, for the Eunice Kennedy Shriver National Institute of Health and Human Development. Randomized controlled trial of progesterone treatment for preterm birth prevention in nulliparous women with cervical length less than 30mm. Am J Obstet Gynecol 2012; 206: s367.
16. O’Brien JM, Adair CD, Lewis DF, Hall DR, Defranco EA, Fusey S, et al. Progesterone vaginal gel for the reduction of recurrent preterm birth: primary results from a randomized, double-blind, placebo controlled trial. Ultrasound Obstet Gynecol 2007; 30: 687-696.

17. Fonseca EB, Celik E, Parra M, Singh M, Nicolaides KH. Progesterone and the risk of preterm birth among women with a short cervix. N Engl J Med 2007; 357: 462-469.

18. Hassan SS, Romero R, Vidyadhari D, Fusey S, Baxter JK, Khandelwal M, et al. Vaginal progesterone reduces the rate of preterm birth in women with a sonographic short cervix: a multicenter, randomized, double-blind, placebo-controlled trial. Ultrasound Obstet Gynecol 2011; 38: 18-31.

19. Romero R, Nicolaides K, Conde-Agudelo A, Tabor A, O’Brien JM, Cetingoz E, et al. Vaginal progesterone in women with an asymptomatic sonographic short cervix in the midtrimester decreases preterm delivery and neonatal morbidity: a systematic review and meta-analysis of individual patient data. Am J Obstet Gynecol 2012; 206: 124.e1-124.e19.

20. Romero R, Nicolaides KH, Conde-Agudelo A, O'Brien JM, Cetingoz E, Fonseca E, et al. Vaginal progesterone decreases preterm birth $<34$ weeks of gestation in women with a singleton pregnancy and a short cervix: an updated meta-analysis including data from the OPPTIMUM study. Ultrasound Obstet Gynecol 2016; 48: 380-317.

21. Romero R, Fonseca EB, O'Brien JM, Nicolaides K et al. Vaginal progesterone to prevent preterm birth in singleton gestations with a short cervix. Am J Obstet Gynecol 2018; 218: 162-180.

22. Dodd JM, Crowther CA, Cincotta R, Flenady V, Robinson JS. Progesterone supplementation for preventing preterm birth: a systematic review and meta-analysis. Acta Obstet Gynecol Scand 2005; 84: 526-533.

23. Sanchez-Ramos L, Kaunitz AM, Delke I. Progestational agents to prevent preterm birth: a meta-analysis of randomized controlled trials. Obstet Gynecol 2005; 105: 273-279.

24. Coomarasamy A, Thangaratinam S, Gee H, Khan KS. Progesterone for the prevention of preterm birth: a critical evaluation of evidence. Eur J Obstet Gynecol Reprod Biol 2006; 129: 111-118.

25. Mackenzie R, Walker M, Armson A, Hannah ME. Progesterone for the prevention of preterm birth among women at increased risk: a systematic review and meta-analysis of randomized controlled trials. Am J Obstet Gynecol 2006; 194: 1234-1242.

26. Dodd JM, Flenady VJ, Cincotta R, Crowther CA. Progesterone for the prevention of preterm birth: a systematic review. Obstet Gynecol 2008; 112: 127-134.

27. Dodd JM, Jones L, Flenady V, Cincotta R, Crowther CA. Prenatal administration of progesterone for preventing preterm birth in women considered to be at risk of preterm birth. Cochrane Database Syst Rev 2013; 7: CD004947.

28. Likis FE, Edwards DR, Andrews JC, Woodworth AL, Jerome RN, Fonnesbeck CJ, et al. Progestogens for preterm birth prevention: a systematic review and meta-analysis. Obstet Gynecol 2012; 120: 897-907.

29. Majhi P, Bagga R, Kalra J, Sharma M. Intravaginal use of natural micronised progesterone to prevent pre-term birth: a randomized trial in India. J Obstet Gynaecol 2009; 29: 493-498.

30. Meis PJ, Klebanoff M, Thom E, Dombrowski MP, Sibai B, Moawad AH, et al. Prevention of recurrent preterm delivery by 17 alpha-hydroxyprogesterone caproate. N Engl J Med 2003; 348: 2379-2385. 
31. O'Brien JM, Adair CD, Lewis DF, Hall DR, Defranco EA, Fusey $S$, et al. Progesterone vaginal gel for the reduction of recurrent preterm birth: primary results from a randomized, double-blind, placebo controlled trial. Ultrasound Obstet Gynecol 2007; 30: 687-696.

32. Rai P, Rajaram S, Goel N, Ayalur Gopalakrishnan R, Agarwal $\mathrm{R}$, Mehta S. Oral micronized progesterone for prevention of preterm birth. Int J Gynaecol Obstet 2009; 104: 40-43.

33. Elimian A, Smith K, Williams M, Knudtson E, Goodman JR, Escobedo MB. A randomized controlled trial of intramuscular versus vaginal progesterone for the prevention of recurrent preterm birth. Int J Gynaecol Obstet 2016; 134: 169-172.

34. Bafghi AS, Bahrami E, Sekhavat L. Comparative study of vaginal versus intramuscular progesterone in the prevention of preterm delivery: a randomized clinical trial. Electron Physician 2015; 7: 1301-1309.

35. Maher MA, Abdelaziz A, Ellaithy M, Bazeed MF. Prevention of preterm birth: a randomized trial of vaginal compared with intramuscular progesterone. Acta Obstet Gynecol Scand 2013; 92: 215-222.

36. Saccone G, Khalifeh A, Elimian A, et al. Vaginal progesterone compared to intramuscular 17-alpha-hydroxyprogesterone caproate for prevention of recurrent spontaneous preterm birth in singleton gestations: a systematic review and meta-analysis of randomized controlled trials. Ultrasound Obstet Gynecol 2017; 49: 315-321.

37. da Fonseca EB, Bittar RE, Carvalho MH, Zugaib M. Prophylactic administration of progesterone by vaginal suppository to reduce the incidence of spontaneous preterm birth in women at increased risk: a randomized placebocontrolled double-blind study. Am J Obstet Gynecol 2003; 188: 419-424.

38. Johnson JW, Austin KL, Jones GS, Davis GH, King TM. Efficacy of 17alpha-hydroxyprogesterone caproate in the prevention of premature labor. $N$ Engl J Med 1975; 293: 675-680.

39. Blackwell SC, Gyamfi-Bannerman C, Biggio JR Jr, Chauhan SP, Hughes BL, Louis JM, et al. 17-OHPC to prevent recurrent preterm birth in singleton gestations (PROLONG study): a multicenter, international, randomized double-blind trial. Am J Perinatol 2020; 37:127-136.

40. Fonseca EB, Celik E, Parra M, Singh M, Nicolaides KH. Progesterone and the risk of preterm birth among women with a short cervix. N Engl J Med 2007; 357: 462-469.

41. Hassan SS, Romero R, Vidyadhari D, Fusey S, Baxter JK, Khandelwal M, et al. PREGNANT Trial. Vaginal progesterone reduces the rate of preterm birth in women with a sonographic short cervix: a multicenter, randomized, double-blind, placebocontrolled trial. Ultrasound Obstet Gynecol 2011; 38: 18-31.

42. Romero R, Fonseca EB, O’Brien JM, Nicolaides K et al. Vaginal progesterone to prevent preterm birth in singleton gestations with a short cervix. Am J Obstet Gynecol 2018; 218: 162-180.

43. Berghella V, Figueroa D, Szychowski JM, Owen J, Hankins GD, Iams JD, et al. 17-Alpha-hydroxyprogesterone caproate for the prevention of preterm birth in women with prior preterm birth and a short cervical length. Am J Obstet Gynecol 2010; 202: 351.e1-351.e6.

44. Conde-Agudelo A, Romero R, Nicolaides K, Chaiworapongsa T, O’Brien JM, Cetingoz E, et al. Vaginal progesterone vs. cervical cerclage for the prevention of preterm birth in women with a sonographic short cervix, previous preterm birth, and singleton gestation: a systematic review and indirect comparison meta-analysis. Am J Obstet Gynecol 2013; 208: 42.e1- 42.e18.
45. Rouse DJ, Caritis SN, Peaceman AM, Sciscione A, Thom EA, Spong CY, et al. A trial of 17 alpha-Hydroxyprogesterone carporate to prevent prematurity in twins. N Engl J Med 2007; 357: 454-461.

46. Combs CA, Garite T, Maurel K, Das A, Porto M, Obstetrix Collaborative Research Network. 17-hydroxyprogesterone carpoate for twin pregnancy: a double-blind, randomized clinical trial. Am J Obstet Gynecol 2011; 204: 221.e1-221.e8.

47. Awwad J, Usta IM, Ghazeeri G, Yacoub N, Succar J, Hayek $S$, et al. A randomized controlled double-blind clinical trial of 17-hydroxyprogesterone caproate for the prevention of preterm birth in twin gestation (PROGESTWIN): evidence for reduced neonatal morbidity. BJOG 2015; 122: 71-79.

48. Caritis SN, Rouse DJ, Peaceman AM, Sciscione A, Momirova V, Spong CY, et al. Prevention of preterm birth in triplets using 17 alpha-hydroxyprogesterone caproate: a randomized controlled trial. Obstet Gynecol 2009; 113: 285-292.

49. Combs CA, Garite T, Maurel K, Das A, Porto M; Obstetrix Collaborative Research Network.. Failure of 17-hydroxyprogesterone to reduce neonatal morbidity or prolong triplet pregnancy: a double-blind, randomized clinical trial. Am J Obstet Gynecol 2010; 203: e241-e249.

50. Durnwald CP1, Momirova V, Rouse DJ, Caritis SN, Peaceman AM, Sciscione A, et al. Eunice Kennedy Shriver National Institute of Child Health and Human cDevelopment MaternalMedicine Units Network. Second trimester cervical length and risk of preterm birth in women with twin gestations treated with 17-alpha hydroxyprogesterone carpoate. J Matern Fetal Neonatal Med 2010; 23: 1360-1364.

51. Senat MV, Porcher R, Winer N, Vayssière C, Deruelle P, Capelle $\mathrm{M}$, et al. Groupe de Recherche en Obstet st Gynecol. Prevention of preterm delivery by 17 alpha-hydroxyprogesterone carpoate in asymptomatic twin pregnancies with a short cervix: a randomized controlled trial . Am J Obstet Gynecol 2013; 208: 194.e1-194.e8.

52. O'Brein JM. Mortality related to 17-OHPC exposure is an important safety outcome. Am J Obstet Gynecol 2013; 209: 282-283.

53. Lim AC, Schuit E, Bloemenkamp K, Bernardus RE, Duvekot JJ, Erwich JJ, et al. 17 $\alpha$-hydroxyprogesterone caproate for the prevention of adverse neonatal outcome in multiple pregnancies: a randomized controlled trial. Obstet Gynecol 2011; 118: 513-520.

54. Norman JE, Mackenzie F, Owen P, Mactier H, Hanretty K, Cooper S, et al. Progesterone for the prevention of preterm birth in twin pregnancy (STOPPIT): a randomized, doubleblind, placebo-controlled study and meta-analysis. Lancet 2009; 373: 2034-2040.

55. Rode L, Klein K, Nicolaides KH, Krampl-Bettelheim E, Tabor A, PREDICT Group. Prevention of preterm delivery in twins gestations ( PREDICT): a multicenter, randomized, placebocontrolled trial on the effect of vaginal micronized progesterone. Ultrasound Obstet Gynecol 2011; 38: 272-280.

56. Brizot ML, Hernandez W, Liao AW, Bittar RE, Francisco RPV, Krebs VLJ, et al. Vaginal progesterone for the prevention of preterm birth in twin gestations: a randomized placebocontrolled double blind study. Am J Obstet Gynecol 2015; 213: 82.e1-82.e9.

57. Klein K, Rode L, Nicolaides KH, Krampl-Bettelheim E, Tabor A; PREDICT Group. Vaginal micronized progesterone and risk of preterm delivery in high risk twin pregnancies: secondary analysis of a placebo- controlled randomized trial and metaanalysis. Ultrasound Obstet Gynecol 2011; 38: 281-287. 
58. Romero R, Nicolaides K, Conde-Agudelo A, Tabor A, O’Brien JM, Cetingoz E, et al. Vaginal progesterone in women with an asymptomatic sonographic short cervix in the mid trimester decreases preterm delivery and neonatal morbidity: a systemic review and meta-analysis of individual patient data. Am J Obstet Gynecol 2012; 206:124.e1-124.e19.

59. Schuit E, Stock S, Rode L, Rouse DJ, Lim AC, Norman JE, etal. Effectiveness of progesterone to improve perinatal outcome in twin pregnancies : an individual participant data meta-analysis. BJOG 2015; 122: 27-37.

60. El-Refaie W, Abdelhafez MS, Badawy A. Vaginal Progesterone for prevention of preterm labor in asymptomatic twin pregnancies with sonographic short cervix: a randomized clinical trial of efficacy and safety. Arch Gynecol Obstet 2016; 293: 61-67.

61. Romero R, Conde-Agudelo A, El-Refaie W6, Rode L, Brizot ML, Cetingoz E, et.al. Vaginal progesterone decreases preterm birth and neonatal morbidity and mortality in women with a twin gestation and a short cervix: an updated meta-analysis of individual patient data. Ultrasound Obstet Gynecol 2017; 49: 303-314.
62. Quist-Nelson J, Parker P, Mokhtari N, Di Sarno R, Saccone G, Berghella V. Progestogens in singleton gestations with preterm prelabor rupture of membranes: a systematic review and metaanalysis of randomized controlled trials. Am J Obstet Gynecol 2018; 219: 346-355.

63. Su LL, Samuel M, Chong YS. Progestational agents for treating threatened or established preterm labour. Cochrane Database Syst Rev 2014; 1: CD006770.

64. Gonzalez-Quintero VH, Istwan NB, Rhea DJ, Smarkusky L, Hoffman MC, Stanziano GJ. Gestational age at initiation of 17-hydroxyprogesterone caproate (17P) and recurrent preterm delivery. J Matern Fetal Neonatal Med 2007; 20: 249-252.

65. How HY, Barton JR, Istwan NB, Rhea DJ, Stanziano GJ. Prophylaxis with 17 alpha-hydroxyprogesterone caproate for prevention of recurrent preterm delivery: does gestational age at initiation of treatment matter? Am J Obstet Gynecol 2007; 197:260.e1-260.e4.

66. Rebarber A, Ferrara LA, Hanley ML, Istwan NB, Rhea DJ, Stanziano GJ, et al. Increased recurrence of preterm delivery with early cessation of 17-alpha-hydroxyprogesterone caproate. Am J Obstet Gynecol 2007; 196: 224.e1-224.e4. 